\title{
(Pobre) Baudelaire en México
}

José Ramón Ruisánchez. University of Houston

jrruisanchez@uh.edu

Resumen: Este texto explora la recepción temprana de Charles Baudelaire en México, tanto como figura biográfica y sobre todo legendaria, como la publicación anterior a la Revista Moderna que suele darse como el primer medio en que se da a conocer en México, primero en Le Trait d'Union, en francés y poco a poco en otras publicaciones como El Universal y Revista Azul.

Palabras clave: Diario Le Trait d'Union, Charles Baudelaire, Prensa mexicana, "Les bons chiens", Breves poemas en prosa.

\begin{abstract}
This piece explores the reception of Baudelaire in Mexico, both as the literary character of his own legend and as the author published several times before Revista Moderna, the usual milestone for his circulation in Mexico. I explore the French-language newspaper Le Trait $d^{\prime}$ Union as well as El Universal and Revista Azul, where his works appeared in Spanish.
\end{abstract}

Keywords: Le Trait d'Union newspaper, Charles Baudelaire, Mexican periodic press, "Les bons chiens", Paris spleen. 
En estas páginas exploro algunas escenas de la recepción de Baudelaire en México. No son, como es natural, exhaustivas. Pero muestran sus etapas principales y, sobre todo, creo que tienen el mérito de llenar huecos sobre su momento inicial, del que hay muchas lagunas.

Asumo, desde el arranque, que recepción quiere decir siempre reinvención: aparición parcial que implica toda una gama de malentendidos y traiciones, carencias e imposibilidades. Pero el trazado de estas carencias, las líneas encontradas de los malentendidos, los borramientos maliciosos de las traiciones, no dejan nunca de ser aparición, no dejan de mostrarnos aspectos importantes del campo en los que se producen.

También, de manera paralela y a través de este caso concreto, pienso diferentes maneras de hacer la historia de las literaturas mundiales, subrayando el plural doble, no sólo por concordancia: sino porque creo que existen - precisamente debido a los caminos azarosos por los que, por ejemplo, llega a existir un tal Carlos Baudelaire, que luego irá recomponiéndose en Charles - una literatura mundial argentina y una literatura mundial mexicana que son muy distintas a las que se enseñan en los departamentos de inglés de circuito del Atlántico del Norte.

Oscilo entre la lectura distante y sus herramientas estadísticas, y la lectura detenida, desde la convicción de que no se debe prescindir de ninguna de las dos porque ambas se necesitan: las preguntas a formular al distant reading, provienen, siempre, inevitablemente de los hallazgos del close reading. 


\section{Google Books Ngram Viewer}

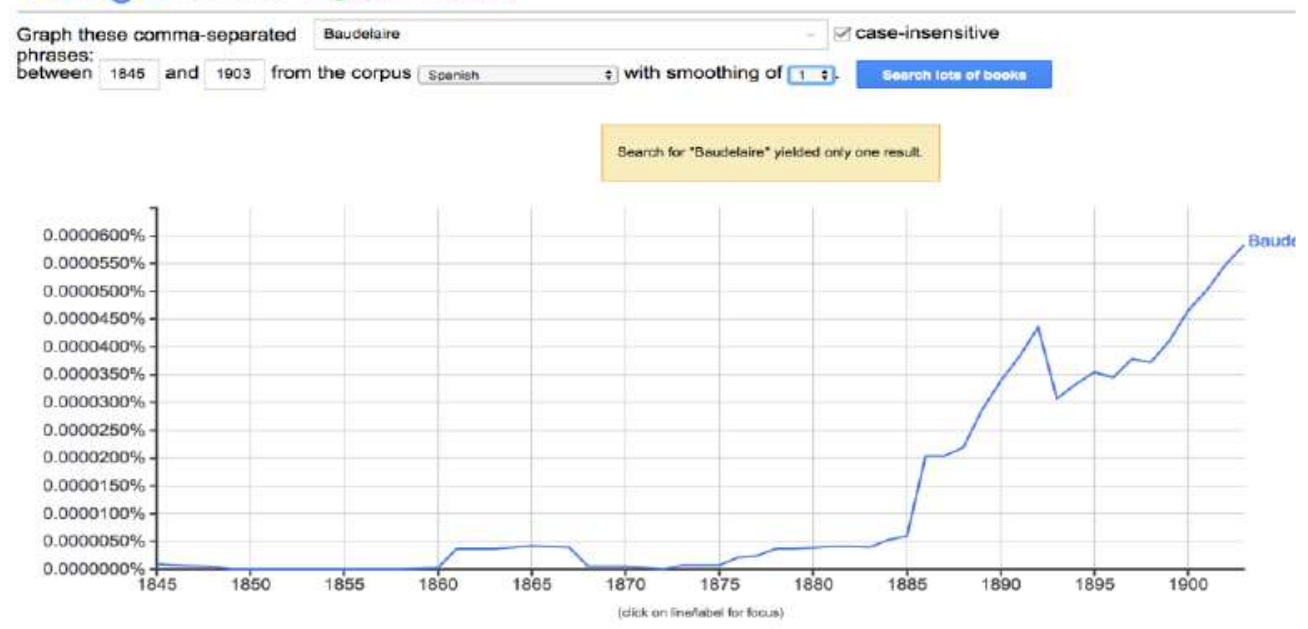

Search in Googie Books:

Fig.1 Ngram de Baudelaire en el corpus de Google books en español.

\section{La prehistoria de Baudelaire en México}

La historia de Baudelaire en México la estableció, como tantas otras cosas, Octavio Paz, quien fija su arranque con la segunda generación modernista. La idea es justa, pues sólo en la Revista Moderna (1898-1903) se publican sus textos en serie y en serio ${ }^{1}$. Incluso Vittoria Borsò, en su importante artículo reciente, parte de allí para pensar en la recepción latinoamericana de Baudelaire.

1 Las obras que se publican en la Revista Moderna son: "À une femme" (1898); "El extranjero", "La desesperación de la vieja", "El confiteor del artista", "Un chusco", "Hymne à la Beauté" / "Himno a la belleza", fragmentos de "Letanías a Satán" (1899); "Embriagaos", "Cada uno con su quimera"(1901); fragmentos de "La literatura honesta" (1902). Los títulos indican si se publicaron en francés o traducidos. 
Después de la Revista Azul (1894-1896) que es el espacio de fundación del modernismo mexicano, la hegemonía del movimiento se produce en la Revista Moderna. Mientras que la primera corresponde a la cima de la trayectoria de Manuel Gutiérrez Nájera, en la segunda cobran importancia José Juan Tablada y Amado Nervo, y las inconfundibles ilustraciones de Julio Ruelas. Ambas han sido rigurosamente estudiadas por Susana Zanetti, Belem Clark de Lara, Serge Zaïteff (por mencionar algunos nombres) y cuentan con ediciones facsimilares modernas. ${ }^{2}$ Esta accesibilidad y el interés que tuvo el modernismo para los poetas críticos — como Paz mismo o como José Emilio Pacheco- tras el desprecio y olvido del que había sido objeto por parte de los miembros de Contemporáneos explican que se haya obviado hasta ahora un segmento importante de la primera recepción: lo que llamo la prehistoria de Baudelaire.

Para intentar su primer esbozo, las herramientas de las humanidades digitales resultan extremadamente útiles. Ya una parte muy importante de los fondos de la Hemeroteca Nacional han sido digitalizados y, aún más importante, los programas de OCR (reconocimiento de caracteres) y el motor de búsqueda de su portal hndm.unam.mx han mejorado enormemente en los últimos años. Esto no quiere decir, como insistiré más adelante, que no siga equivocándose.

El ejemplo crucial es Le Trait d'Union, el diario donde aparece la primera mención de Baudelaire en México. Le Trait

\footnotetext{
${ }^{2}$ Mi propia contribución al tema, es "El ethos modernista". En este artículo discuto la modernidad de estas revistas en términos del pensamiento de Bolívar Echeverría y del interior como lo analizó Walter Benjamin.
} 
d'Union, que llevaba el nada modesto subtítulo de Journal Universel, se publica por primera vez en 1857 y dura hasta 1892, aunque sólo salió de manera ininterrumpida después de 1868, acabada la intentona de Napoleón III (el llamado "imperio" de Maximiliano) y restablecida la presidencia de Benito Juárez.

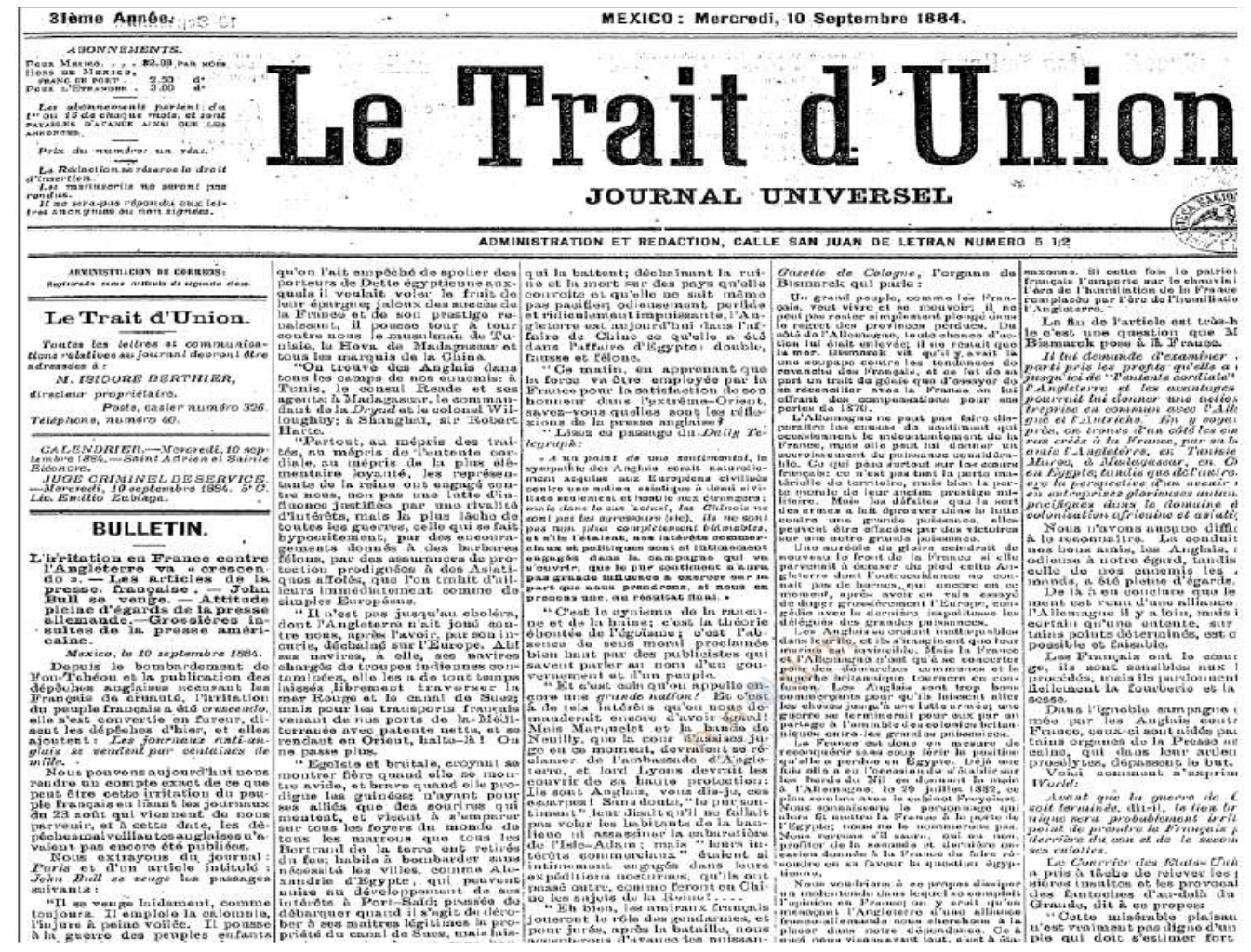

Fig. 2 Le Trait d'Union 10-IX-1884. Digitalizado por la HNDM.

Se trata de una publicación en francés, con sede en la Ciudad de México, que justamente unía las noticias de Francia (y a veces de la pauvre Belgique) con notas y anuncios sobre México. Así. en un ejemplar podían combinarse una discusión del senado francés, con la noticia de la captura de un enorme 
cocodrilo en el río Coatzacoalcos; la novela del folletón, por ejemplo de Ponson de Terrail, con los anuncios de abogados, profesores o restaurantes de la Ciudad de México.

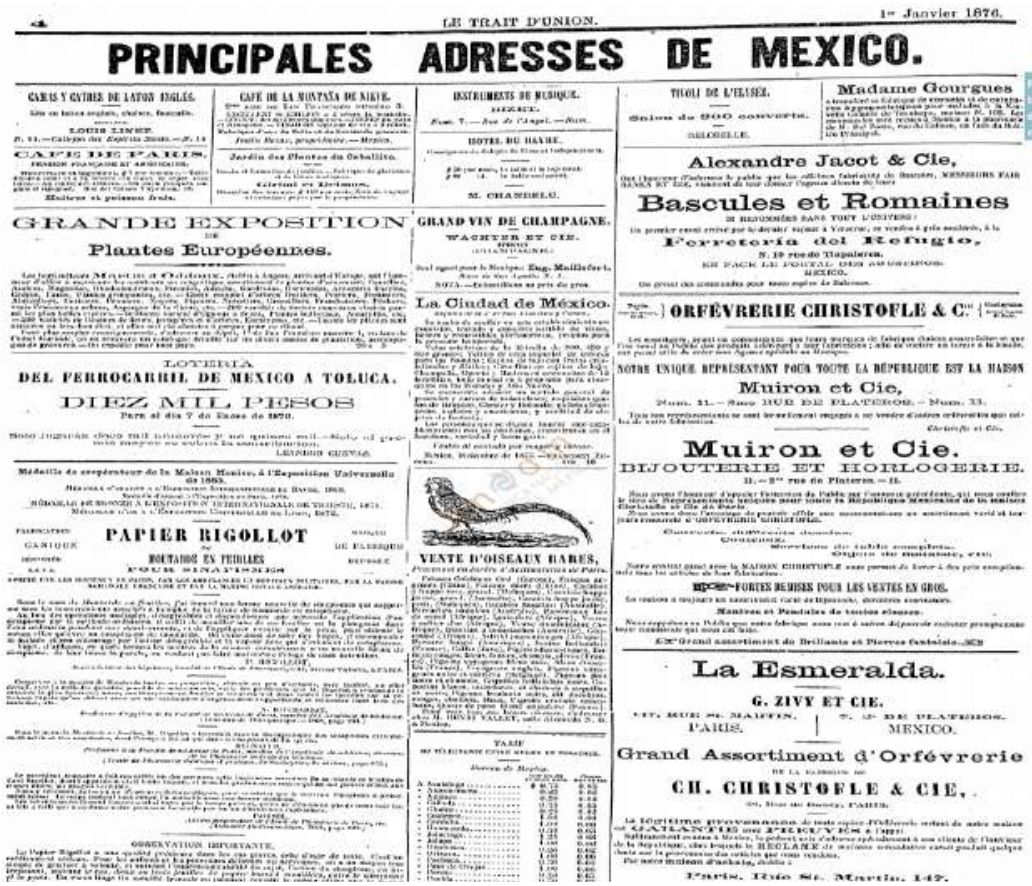

Fig. 3 Le Trait d'Union 1-I-1876. Digitalizado por la HNDM.

En el número del 29 de junio de 1876 se publica una pequeña viñeta, protagonizada por Charles Baudelaire. "El poeta de Las flores del mal', dice, poseía un solo sombrero, terriblemente maltratado, que atraía las miradas escandalizadas de quienes lo rodeaban. Llegó el día en que uno de sus amigos no pudo soportar más el escarnio y le exigió que fuese con él, a ver a su sombrerero, implicando que se hará cargo de la cuenta. Baudelaire se niega rotundamente: "Me quedo con mi sombrero". 
—Le ruego que me diga por qué.

- Porque espanta a los falsos amigos (p. 3).

Es muy probable que el relato sea apócrifo, parte de lo que la crítica denomina "baudelaieriana": ese suplemento narrativo pseudobiográfico que intenta habitar el tono y los ambientes de los textos escritos por el poeta. ${ }^{3}$ El valor de la baudelairiana no radica, desde luego, en su factualidad sino en algo más. Cuarenta años antes de que aparezca la primera versión en español de Las flores del mal (la del catalán Eduardo Marquina), al menos para cierta comunidad mexicana o residente en México, Baudelaire es ya un personaje que habita la textura de su propia leyenda, y desde las reglas de su singularidad se erige como arquetipo de una individualidad. Es capaz de erigir y exigir otro tipo de gestos por encima y más allá del buen gusto, superando la moda como normalidad, aboliendo la tiranía de los modales, sorteando una autorregulación social.

Ahora bien, es importante subrayar que seguían siendo aspiracionales en la sociedad mexicana de este tempranísimo Porfiriato. Acaso esto explica por qué, en la prensa en español,

${ }^{3}$ Ya muy temprano en la recepción del ámbito español, estos libros que nunca existieron ejercieron una fuerte atracción. Por ejemplo, el incómodo Juan Valera escribió:

Dicen que Baudelaire, ya en los últimos años de su vida, trazó el plan de un drama o novela, El criminal dichoso, que es lástima dejase de escribir, pues con él hubiera acabado de aterrar a los burgueses. El héroe, desechando ridículas preocupaciones y temores y escrúpulos, debía cometer con éxito brillante todas las atrocidades más inauditas: matar a su padre, violar a su madre y a su hermana, deshonrar a su hermano y vender a su patria. Todo ello lo habría de ejecutar con tal destreza que, además de mucho placer, había de proporcionarle la estimación pública y cuantiosos bienes de fortuna con lo cual, retirado en deliciosa quinta, en el país más bello y en el clima más benigno, había de vivir en perpetuo idilio, sin nada más que desear. (OC II 680, citado en Aggeler 6) 
la baudelairiana, sobre todo la que invoca a un diablo ejemplar, resulta mucho más popular que los textos autógrafos del poeta. Las anécdotas de transgresión logran, de manera muy económica, crear una burguesía —que, insisto, apenas existía en germen- y escandalizarla. Si uno puede épater le bougeois, también comprueba su existencia.

Pero no puedo abandonar aún Le Trait d'Union pues es allí también donde aparece por primera vez un texto del poeta. El 4 de julio de 1879 aparece reproducido "Les bons chiens", uno de sus poemas en prosa.

En un número reciente de la Yale French Studies dedicado a Baudelaire, Julien Weber explora la genealogía de este texto. En parte, afirma, proviene de la "fisiología", que exploraba de manera humorística a los tipos comunes en la ciudad moderna, y que surge como reacción a las leyes de 1838, que volvieron más severa la censura sobre la prensa, llevando a la publicación de sátiras de índole menos política. Por otra parte (sigo con Weber) Baudelaire renuncia a la distancia del naturalista, prefiriendo la cercanía al animal que aparece de manera ejemplar en el pasaje de Laurence Sterne donde el personaje le da su último macaron a un burro. ${ }^{4}$ Se produce humor, pero no de la índole de la que practica Voltaire, sino uno mucho más compasivo.

\footnotetext{
${ }^{4} \mathrm{El}$ pasaje en cuestión:

In saying this, I pull'd out a paper of 'em, which I had just purchased, and gave him one - and at this moment that I am telling it, my heart smites me, that there was more of pleasantry in the conceit, of seeing how an ass would eat a macaroon - than of benevolence in giving him one, which presided in the act. (https://en.wikisource.org/wiki/Tristram_Shandy/Chapter_4)
} 
Me pregunto - ya que en la publicación en Le Trait d'Union no hay una marca paratextual que señale "Les bons chiens" como un texto literario, al modo que sucedía de manera clarísima en el folletón - si la firma bastó para activarlo de este modo. Si alguien reconoció que se trataba de uno de los textos (de hecho el que lo cierra) de "El Spleen de París".

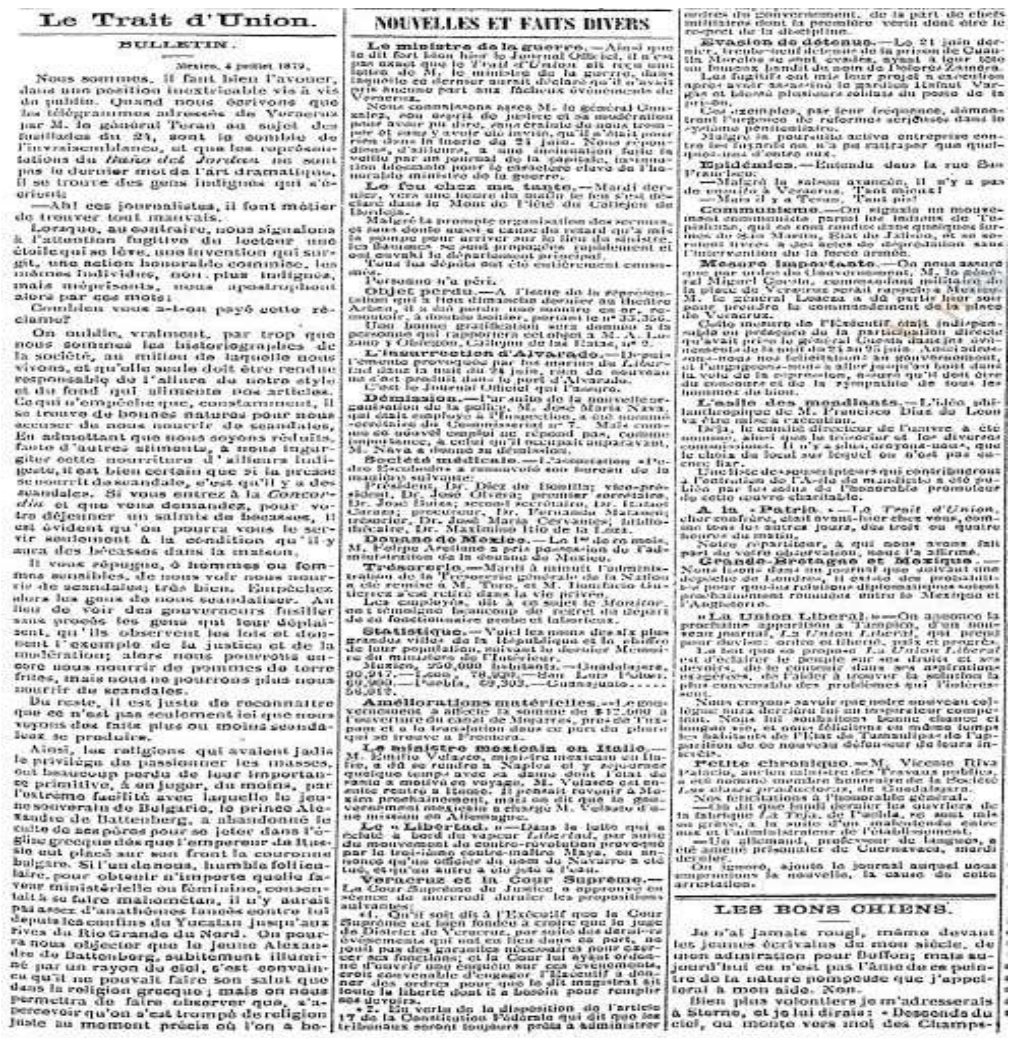

Fig. 4 Le Trait d'Union 4/VII/1879. Digitalizado por la HDNM.

Pienso en la serie de datos que constituyen el contexto para aventurar respuestas a esta pregunta. Ya en fecha muy 
temprana ¡1857 nada menos! Cecilia Böhl de Faber, mejor conocida como Fernán Caballero usa como epígrafe a su novela Clemencia un fragmento de Baudelaire. El colombiano José María Torres Caicedo lo menciona en su ensayo de 1863 sobre Hilario Ascasubi. En un artículo sobre Poe, como sucederá después tantas veces, la Revista Hispano Americana de 1867 lo menciona como su traductor. En 1881 aparece el importante artículo de José Martí sobre Baudelaire en su "Sección Constante". En el ámbito mexicano, en las memorias de Sebastián Lerdo de Tejada (publicadas en 1889, pero seguramente redactadas mucho antes, pues se trata de un libro póstumo) un epígrafe de Baudelaire: Résigne-toi, mon coeur; dors ton sommeil de brute, que copia de "Le goût du néant" partiendo el alejandrino en sus dos hemistiquios. ${ }^{5}$

Se trata de, digamos pre-lecturas, de testimonios y comentarios de quienes lo conocen y lo manejan (o hacen como si lo manejaran) con soltura. Este contexto va creando un deseo, y finalmente una urgencia que permiten que Baudelaire sea verdaderamente leído. Un caso interesante que nos permite analizar este cambio de momento, insisto, anterior

\footnotetext{
${ }^{5}$ Lerdo de Tejada-conocido por haber ocupado la presidencia durante los cuatro años que mediaron entre la muerte de Benito Juárez (1872) y el triunfo del plan de Tuxtepec (1876) que llevaría a Porfirio Díaz al inicio de su larga dictadura - nació en la ciudad veracruzana de Xalapa, menos importante que el puerto, en una familia que vivía del pequeño comercio. Más que por sus medios económicos, logró educarse por sus méritos académicos: sus resultados sobresalientes en la escuela elemental, le permitieron asistir a la Palafoxiana en Puebla, una ciudad mucho más importante y próspera que Xalapa, donde se va perfilando hacia la carrera religiosa, pero la interrumpe en 1841, cuando ya había recibido las órdenes menores. Una década después lo ha reclutado una logia masónica y se ha graduado como abogado del Colegio de San Idelfonso.

Por supuesto, esta pequeña novela me parece importante porque dibuja el perfil del joven católico que vira al liberalismo cuando deja la ciudad de provincia: el personaje de de Balzac es el lector ideal de Baudelaire.
} 
al que marca el lugar común oficial, es el de la revista $L a$ República Literaria, publicada en Guadalajara, la segunda ciudad del país. En el número de marzo de 1886, el narrador realista José López Portillo y Rojas escribe:

Muy perjudicial ha sido el ejemplo que a este propósito nos han legado algunos genios poéticos de los más renombrados y aplaudidos, comenzando por Byron, el noble y rico lord, cuya extravagancia y relajadas costumbres han sido el objeto de los comentarios de Europa durante medio siglo. Los imitadores y émulos de este hombre extraordinario, siguieron sus pasos en el camino de la corrupción, habiéndose formado a su influjo una escuela cuyo credo ha sido la negación más impía y desconsoladora, y cuya línea de conducta ha consistido en la crápula erigida en sistema. Musset perteneció a ella y vivió encenagado en los vicios y esterilizado en hora temprana por los excesos. Gerardo de Nerval, enloquecido por sus desórdenes, se ahorcó él mismo, en noche oscura, suspendiéndose a la reja de un sucio callejón de París. Carlos Baudelaire murió loco a causa del uso constante del opio. Edgardo Poe sucumbió ahogado por la bebida o presa del delirium tremens, en la ciudad de Baltimore sobre el embaldosado de la vía pública, sin que nadie presenciara su agonía, en altas horas de la noche (1886, p. 145).

Hasta aquí parecería un poco la misma tónica de los repetidores de la baudelairiana que reciclaba los perennes tópicos del maldito. Pero hay un viraje, una diferenciación que me parece interesante en el párrafo siguiente:

Así como Byron formó escuela, los imitadores que ha tenido y que han alcanzado celebridad, la han formado asimismo en las regiones más bajas del mundo literario, y, a ejemplo de los poetas mencionados y de otros muchos de 
vida disipada y escandalosa que fuera largo enumerar, ha habido incontables poetillas de tercera y cuarta clase que, juzgando alcanzar renombre por medio del vicio, se han dejado arrastrar por sus pasiones, satisfechos con parecerse a Poe sólo en lo ebrios o a Musset únicamente en el desenfrenado erotismo; habiendo no pocos que han juzgado poner la corona a su renombre, saltándose la tapa de los sesos como Larra (pp. 145-146).

Lo que para mí señala este párrafo es la distinción (y sobre todo la posibilidad de distinguir) entre el gran diablo y el pobre diablo; no es lo mismo el maldito de talento que el maldito epigonal, que imita la vida sin alcanzar la obra. Señala también el alba de un segundo momento en que la bohemia pasa de ser una vida imposible o sólo posible en la metrópolis, a convertirse en una sociabilidad que existía de hecho en las ciudades mexicanas.

En el número de septiembre de la misma revista, se traduce un artículo del importante crítico Ferdinand Brunetiére, director de La Revue de Deux Mondes, donde éste traza una distinción importante entre Lamartine (durante mucho tiempo el poeta francés mejor recibido en México, por encima de Victor Hugo, incluso) y otros poetas de la pléyade francesa: "Y en efecto, no es su género el de Carlos Baudelaire ni aun el de Alfredo de Vigny, que se dedicaron casi únicamente a traducir lo que creían encontrar en sí mismos más diferente de sus semejantes" (1886, p.91). Esta distinción, entre el poeta que dice de manera incomparable lo común frente a los que privilegian sus singularidades, aunque no producto de la crítica 
mexicana, es una huella de lo que formaba el contexto de recepción de la poesía en la época.

Estas coordenadas intermitentes de la constelación de Baudelaire en México cristalizan muy a principios de 1892. El primer domingo del año, el del 3 de enero, se publica en el diario El Universal de Rafael Reyes Spíndola lo que, hasta donde sé es la primera aparición en español en la prensa mexicana. Se trata de una traducción del soneto "Le révenant" que, al ser vertido en octasílabos, convierte sus tercetos en cuartetas. Sin embargo, si uno intenta buscarlo usando el HNDM, no lo encontrará. Porque el entonces muy joven José Juan Tablada, quien después tendría un rol crucial en el paso del modernismo a la vanguardia, lo firma con su propio nombre.

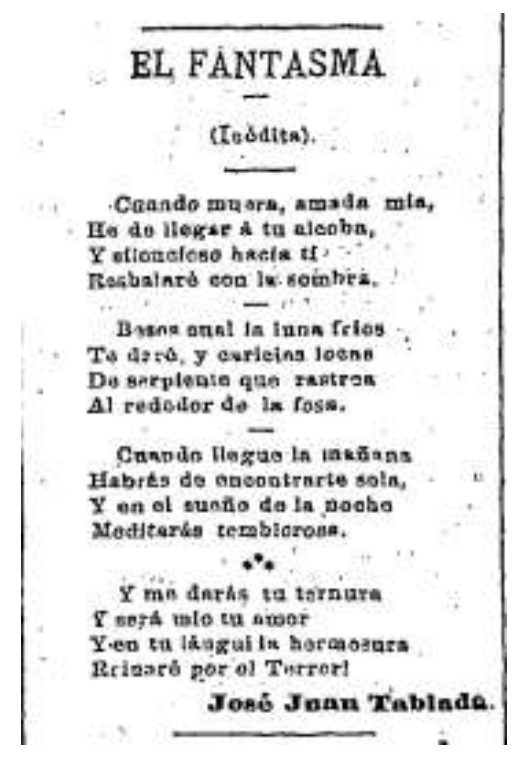

Fig. 5 El Universal 3/I/1892. Digitalizado por la HNDM. 
Menos de una semana después, el 8 de enero, en El Partido Liberal le cae un palo. "Cortadillo" — probablemente José Anacleto Castillón (1860-1940), como me ha señalado Luz América Viveros - publica en su columna el original en francés y hace una crítica muy filosa no sólo del plagio ( $E l$ Universal lo ha aclarado casi de inmediato) sino de la versión de "Tabladita":

Véase si hay diferencia entre estos dos pensamientos:

1o Quiero yo reinar en tu vida y en tu juventud por el terror, así como otros reinan por medio de la ternura.

2o Por medio del terror, reinaré en tu lánguida hermosura y me darás tu ternura y tu amor será mío.

Baudelaire, como se ve, conténtase con afirmar que reinará por el terror y sin afirmar que obtendrá así ternura y amor, porque afirmarlo hubiera sido una barbaridad (p.1).

Esto, por supuesto, muestra que al menos en México la traducción de Baudelaire y la reflexión crítica sobre su posibilidad nacen con apenas días de diferencia. Pero también que para la última década del siglo XIX, el robo que planeaba Tablada era imposible pues había gente que tenía el volumen en sus libreros y lo conocía lo suficientemente bien como para detectar el plagio de inmediato. ${ }^{6} \mathrm{Ha}$ terminado su prehistoria.

Al mismo tiempo, pero ya de manera inevitable, la traducción de Baudelaire avanza. En 1895 aparece por primera

\footnotetext{
${ }^{6}$ Desde luego no es el único caso en el ámbito hispánico. Al buscar en Archive.com o en books.google tratando de trazar la diseminación de un fragmento magnífico, "j'ai senti passer sus moi le vent de l'aile de l'imbecillité", que aparece en la sección 86 de sus Fusées, me encuentro con la sorpresa de que Pío Baroja la secuestra sin mayor ceremonia es su cuento "El grito del mar": "El ala de la imbecilidad venía a acariciar dulcemente mi espíritu".
} 
vez mencionado en la Revista Azul (Carlos Díaz Dufoo dice que la juventud que lee a Baudelaire también asiste cada año a ver la representación del Don Juan Tenorio de José Zorrilla); en un artículo sobre música de este mismo año se citan algunos versos suyos que se dejan sin traducir. Además, se vierten "La desesperación de la anciana", "Los paraísos artificiales" y "El haschich". En El Comercio de Morelia se publica, en 1895, "Las ventanas", una traducción decorosa de "Les fenêtres", otro de los breves poemas en prosa.

Aquí hay que acelerar un poco para llegar a la época en que finalmente se dan las traducciones de Baudelaire que constituyen su cimiento canónico: las debidas a Balbino Dávalos, Atenor Lescano y a un Tablada que ya no es Tabladita sino un poeta en plenitud de capacidades literarias; a ellos pero, sobre todo, a Enrique González Martínez, quien en Jardines de Francia publicado como volumen en 1915 entrega lo que los prologuistas de su edición más reciente, Luis Vicente de Aguinaga y Ángel Ortuño llaman "poemario de traductor" (7) (y no un florilegio, pues no se trata de ofrecer un panorama crítico, sino personal, acomodado con el criterio del oído).

De este mismo libro dice José Emilio Pacheco, a quien dedicaré la última parte de mi ponencia, que se trata del "mejor libro de versiones poéticas que produjo el modernismo y que en gran parte alimentó la segunda Antología francesa de [Enrique] Díez-Canedo, aparecida póstumamente y terminada 
por su hijo Joaquín ${ }^{7}$ y por Guillermo de Torre, aunque sin crédito en la edición" (II 343).

Con este párrafo quiero enganchar la generación del modernismo, con el lector que la construye críticamente en México. Primero con la Antología que publica en 1971, en el centenario de Amado Nervo, pero incansablemente a lo largo del resto de su carrera. En este momento se vuelve necesario pensar, o al menos comenzar a pensar, lo que significa para los estudios de Baudelaire (y para prácticamente cada aspecto de la literatura mexicana) la selección en tres tomos (con más de 2000 páginas en total) del Inventario, el periodismo cultural de Pacheco. Quien es el primer intelectual mexicano en comprender cabalmente la importancia de Walter Benjamin, tanto en la lectura del siglo XIX europeo como una topología en torno al yo móvil de Baudelaire, como para comprender, desde ese replanteamiento radical, el XIX mexicano (que sólo termina con la tormenta de la Revolución). Dice Pacheco en uno de los textos que le dedicó a Benjamin, originalmente publicado en 1990:

El Passagenwerk es una indagación sobre los orígenes de la modernidad y sobre todo una crítica del progreso-el mito de la omnipotencia humana-que crea su propia predeterminación. Para ello Benjamin reunió como en un bazar lo más diverso y trazó las interrelaciones entre la tecnología, los afectos de la industrialización en el arte, la conciencia entre la aparición de las masas y la producción en serie, la flor como emblema del pecado, el río Sena, la moda, el tedio, la

\footnotetext{
${ }^{7}$ El mismo Joaquín Díez-Canedo que hizo, en todos los sentidos, una de las editoriales fundamentales de la década de 1960: Joaquín Mortiz.
} 
destrucción y la reconstrucción de París, la publicidad, los cafés, la invención de la adolescencia, el paseante, la Comuna, el coleccionista, los periódicos, los subterráneos, las catacumbas, las novelas de folletín, los ferrocarriles y sus estaciones, las cloacas, las bohemia, Saint Simon, Baudelaire, Fourier, Marx, Victor Hugo, Zola, la construcción en hierro, los bulevares, los dioramas, el juego, la prostituta, Daumier, la fotografía, las barricadas, la bolsa de valores, las exposiciones mundiales, las sectas, el interior, los fósiles, los fetiches, las ruinas, el calidoscopio.

Este caos que refleja el desorden de la ciudad moderna Benjamin intentó ordenarlo como se disponen las mercancías en una tienda de departamentos (II, p. 604).

Es un précis fiel a las obsesiones que trabajaron a Baudelaire, lo que no es extraño cuando la carpeta más poblada de los ficheros de Benjamin sea la J: dedicada íntegramente al escritor de la vida moderna.

Pacheco entendió la cultura de la misma manera compleja. Pero lo que para Benjamin fue el París del medio siglo XIX, para Pacheco fue la Ciudad de México justamente de su final y los inicios del XX: los años que he venido trabajando en estas páginas. $Y$ aunque es generoso con Salvador Novo, con Alfonso Reyes, con José Vasconcelos, con Martín Luis Guzmán, no me cabe ninguna duda de que el protagonista de estas páginas, que son su propio "Proyecto de los pasajes", es Ramón López Velarde, su centro: el escritor en quien todas las tempestades de su tiempo convergen para formar el sustrato de una obra insustituible.

Pero, centralmente para lo que aquí interesa, hay que señalar cómo es en López Velarde donde la herencia inicial de 
Baudelaire, en sus metamorfosis mexicanas, adquiere por fin forma propia. En lo mejor de su poesía, en vez de suspirar por una París en la que la Ciudad de México jamás se transformaría, reinventa Jerez, su pequeña ciudad natal de provincia, de manera entrañable e irónica, no en su gloria presente (insisto, esta gloria en el contexto mexicano es ilusoria) sino como ruina. Pacheco lo pone así: "Como después López Velarde, Laforgue medita en la polis desde su última fase: la necrópolis" (II, p. 328). Pacheco especula si López Velarde leyó a ese brillante discípulo de Baudelaire que fue Jules Laforgue, a quien pudo haber conocido en el original o a través de Lugones. Al final es una de esas especulaciones eruditas, en las que no queda excluida la ficción y que marcan una de las zonas de afinidad entre Pacheco y Borges.

Lo importante al final no es el hecho de si López Velarde leyó o no a Laforgue, sino que, a semejanza de éste, se acerca a Baudelaire de manera oblicua, interponiendo una distancia productiva. En vez de tratar de salvar la imposible distancia que lo separa de Baudelaire, López Velarde debe su genio a que sabe incorporar temáticamente esta imposibilidad. Escribe en "El rebozo de seda", uno de los poemas más citados de su Sangre devota (1913):

(En abono de mi sinceridad séame permitido un alegato: entonces era yo seminarista sin Baudelaire, sin rima y sin olfato)

Esta distancia inicial, nunca desaparece en la poesía de López Velarde; habrá leído a Baudelaire con pasión, pero en su 
flannerie siempre carga con los paseos de la placita pueblerina y su "edén subvertido" y eso es lo que permite una lectura singular de Baudelaire, la posibilidad de partir precisamente de una recepción originalísima y compleja, que modifica al modelo.

\section{Referencias Bibliográficas}

Aggeler, W. F. (1971). Baudelaire Judged by Spanish Critics, 1857-1957. Athens, Georgia: U. of Georgia P.

Cortadillo. "Peor está que estaba". El Partido Liberal (8/I/1892) http://www.hndm.unam.mx/consulta/resultados/visualizar/ 558a334b7d1ed64f169345of?resultado=1\&tipo=pagina\&intP agina $=1 \&$ palabras $=$ Cortadillo

Borsò, V. (2007). "Charles Baudelaire et la modernité en Amérique Latine" en WalterBruno Berg y Lisa Block de Behar. France-Amérique Latine: croisements de lettres et de voies. París: L'Harmattan, pp. 55-80.

Brunetière, F. (1886). "La poesía de Lamartine". La República Literaria (IX-1886), pp.89-96. [http://www.hndm.unam.mx/consulta/resultados/visualizar $/ 558 \mathrm{a} 32 \mathrm{~d} 67 \mathrm{~d} 1 \mathrm{ed} 64 \mathrm{f} 168 \mathrm{bbbdc}$ ?resultado=267\&tipo=pagina\&i ntPagina $=90$ ]

González Martínez, E. (2014). Jardines de Francia. Prol. Luis Vicente de Aguinaga y Ángel Ortuño. México: UNAM, 2014.

López Portillo y Rojas, J. (1886). "Los poetas". La República literaria (III-1886) pp. 129-149. [http://www.hndm.unam.mx/consulta/resultados/visualizar 
/558a32d57d1ed64f16

8 ba6ed ?resultado $=74 \&$ tipo $=$ pagina\&intPagina $=132]$

López Velarde, R. La sangre devota. [http://www.cervantesvirtual.com/portales/ramon_lopez_ve larde/obra-visor/la- sangre-devota--o/html/ooo689a85037-4ef7-8e47-3fod8577166c_1.html\#I_2_]

Pacheco, J. E. (2016). Inventario: antología. 3 tomos. Ed. Eduardo Antonio Parra et al.México: ERA, 2016.

Ruisánchez Serra, J. R. (2018). "El ethos modernista". Belem Clark de Lara and Ana Laura Zavala (eds.). Literatura mexicana siglo XIX II. México: UNAM, en prensa.

Sterne, L. The Life and Opinion of Tristram Shandy, Gentleman [https://en.wikisource.org/wiki/Tristram_Shandy]

Weber, J. (2014). "Jetter sa langue aux chiens: Collective Memory in Baudelaire's 'Les Bons Chiens'". Yale French Studies. 